\title{
Development of Curriculum Units as Basic Course for Calculus Provided for Freshmen with Low Academic Achievement
}

\author{
Yuang-Tswong Lue ${ }^{1, *}$ \\ ${ }^{1}$ Taipei Chengshih University of Science and Technology, Taipei, Taiwan \\ *Correspondence: Taipei Chengshih University of Science and Technology, Taipei, Taiwan. E-mail: \\ lue.yt@msa.hinet.net
}

Received: May 3, 2015 Accepted: July 20, 2015 Online Published: August 24, 2015

doi:10.5430/jct.v4n2p47 URL: http://dx.doi.org/10.5430/jct.v4n2p47

\begin{abstract}
This study was to design, develop, and investigate instructional units for freshmen with low academic achievement to learn before they study calculus. Because the concepts, skills, and theories of function are fundamental for the calculus course but the below average students were not familiar with the basic knowledge and ability in function when they studied in the high schools and it will affect their learning calculus, the investigator in this study has analyzed the calculus course to find out the relevant functional concepts, skills, and theories and taken some actual research studies as references to deliberately design, compile, and write an instructional unit on function. Then the teaching material was tried out in the classroom. During trying out the unit, the investigator found that students were also unfamiliar with the concepts and operations of numbers and sets. Therefore, the investigator thought that it is indispensable to integrate the content of numbers and sets into the course. Finally the curriculum units including numbers, sets, and functions have been completed to be a basic course for calculus. After preparing the curriculum units, the teaching materials were sent to experts to ask for reviewing and giving feedback for revising the content. Then the curriculum will be tried out again in the beginning of the calculus course to test the degree of appropriateness and find where should be revised again. During the next year, a formal instruction will be carried out. Finally, it is to complete a set of curriculum units on number systems, sets, and functions for freshmen to take as basic content for calculus course.
\end{abstract}

Keywords: curriculum units on number system, set, and function; basic content for calculus course; trying out the curriculum units

\section{Introduction}

This study was to design and develop curriculum units for freshmen to take as basic contents before learning calculus. In the beginning, the investigator made effort only to develop a curriculum unit on function because the concepts, procedures, and theories of functions are essential for studying calculus. During trying out the unit, the investigator found that students were also unfamiliar with the concepts and operations of numbers and sets. Therefore, the investigator thought that it is indispensable to integrate the content of numbers and sets into the course. Finally the curriculum units including numbers, sets, and functions (including algebraic functions, absolute value functions, exponential functions, logarithmic functions, trigonometric functions, and inverse trigonometric functions) have been completed to be a basic course for calculus.

Numbers, sets, and functions together with the related concepts are fundamental content for learning calculus. However, many college students did not get familiar with those contents when they studied in high schools. It will affect students' learning calculus. Although the high school curriculum and instruction provide sufficient content in numbers, sets, and functions for students to learn calculus in college, the below average students still have problems in the content. Therefore, this study had been planned to design and develop a pre-calculus course for freshmen to learn to help them to learn limit, differentiation, and integration thereafter.

During the past decade, the relevant content of function was integrated into the instruction of calculus when it was necessary in my course. Perhaps integration could give students only piecewise knowledge of function instead of continuous and integral knowledge and procedures. If we can review the content of function before teaching calculus to renew students' memorization and let them get inspired to obtain correct concepts, knowledge, and procedures on 
function, it will establish a good base for them to learn calculus.

According to my research studies during the past years, I found that many students in junior high school, senior high school, or junior college were unclear about functional concepts even they had learned those concepts in the junior high school. When they were asked about the meaning of function, they could only give examples without any explanation or only with incomplete interpretation. Few students could give the essential meaning or definition of function. In addition, rare students could give any non-example of function. Most students could only do calculations instead of understanding abstract concept. The content of function in the junior high school curriculum contains only linear and quadratic function. Although there are examples of function with discrete variable and examples of rational function in that curriculum content, many first year students in the junior college misunderstood that only linear or quadratic functions are then functions. Being linear or quadratic was used as criterion to distinguish whether the given examples in any representation is a function. They even could not accept that an absolute function or rational function is a function because the independent variable $\mathrm{x}$ cannot be put inside the sign of absolute value or in the denominator. They used to give incorrect reasons.

The initial purpose of this study was to design and develop a curriculum unit on function for college freshmen to take as basic content before learning calculus and to explore the following questions:

(1) What content of function should be included in the curriculum unit in terms of experts' opinions?

(2) When the curriculum unit is tried out in the college with low level students, how appropriate is the content and what content should be revised or added?

(3) Are there any misconceptions that freshmen have when they study the curriculum unit?

(4) Is there other content that should be included for pre-calculus course?

\section{Literature Review}

\subsection{Experience of Developing a Curriculum Unit}

In 1984, I developed a lesson on the topic of stem-and-leaf plot to do a pilot study at the university of Georgia to see how appropriate the content is, what learning difficulties that students have, and what content should be revised. Then I went back to Taiwan to design and develop a descriptive statistics curriculum unit that was to be integrated into the mathematics curriculum for Grade 11 students in the business colleges. Twenty-eight experts in Taiwan were asked to comment on the curriculum materials and give advice for improving the content. The detailed results were reported in Lue (1985). From this study, I understood that not only design and compilation of curriculum is important for the development work but also the process of trying out the curriculum materials are indispensable. Because only trying out the curriculum can find out the students' learning difficulties and the defects of the teaching materials to improve the content and propose useful teaching guide. On the other hand, I recognized that the arrangement of spiral curriculum is helpful for students' learning. Spiral arrangement of the curriculum content used to be advocated by educators. Fennema, Carpenter, \& Franke (1992) also advocated cognitively guided instruction. The gist is to ask the teacher to recognize the cognition status of their students to give instruction according to their capabilities. Of course, it is an important principle in developing a curriculum material and teaching.

\subsection{Students' Understanding about the Concepts of Numbers}

Lue $(2007,2008)$ pointed out that "comparing students' performances on five kinds of definition domains, the order of the difficulty was about in the form FNZRQ in the pilot study and in the form FZN' $Q R$ in the main study from the easiest to the most difficult (here $\mathrm{F}$ stands for the finite set including $-1,0,1$, and $2, \mathrm{~N}$ stands for the set of natural numbers, N' stands for the set including natural numbers and other three integers $0,-1$, and $-2, \mathrm{Z}$ stands for the set of integers, $\mathrm{Q}$ stands for the set of rational numbers, and $\mathrm{R}$ stands for the set of real numbers)....It is easy to see that students' performances were affected by the corresponding forms of function and its definition types. Moreover, students could deal with constant function and finite domain best." Lue (2004, 2005) also said "Students were only familiar with simple routine algorithm. But they could not deal with more complicated data, such as radicals. It is easier for students to get extrema for bounded monotonic functions but more difficult for them to find extrema for unbounded functions." In addition, he mentioned "Although two variables have linear relationship, students were unable to point out the function relation between the two variables. To get the function expression from a given algebraic expression was an uneasy task for them. It was more difficult to ask students to get domains of function, especially the range. Students used to draw a continuous graph for even a function with discrete domains. Few students could draw the graph or find the extrema for the irrational function $\mathrm{h}(x)=\sqrt{x}$." Liu (2006) also found that 
students used to think that a function should be continuous and tend to regard that a point-wise graph cannot represent a function.

\subsection{Students'Learning Difficulties on Function}

Lovell (1971) found that middle school students have miscellaneous misconceptions and puzzles in learning functions. Only a few elder students could deal with composite functions. Markovits, Eylon, \& Bruckheimer (1986 $\& 1988$ ) found that students could not understand functional concepts, such as domain, range, pre-image, and image. Students were also puzzled with constant function, piecewise function, and point-wise function. Students used to cite linear functions as examples for function and use algebraic expression or graph as the representation of a function. Moreover, it is more difficult to transform graph to algebraic expression than vice versa. Tall \& Vinner (1981) and Vinner \& Dreyfus (1989) found that it is a difficult task for students to reflect from their brain although the definition of function is short and brief. To deal with problems, students used to reflect concept image instead of definition. Concept images were formed from their experiences and might distort correct cognition, such as regarding functions being a formulated expression.

In Taiwan, many researchers found that students had a lot of misconceptions or alternative conceptions in functional concepts and even could not distinguish example or non-example from representations of functions. My experiences tell me that students were easier to do simple procedure tasks, such as computing function value (image), than to deal with concept questions. In 2001, I interviewed two junior middle school students: one is a Grade 9 girl student whose academic performance was average and the other is a Grade 8 boy student whose academic performance was above average. Both could use algebraic expression $\mathrm{f}(\mathrm{x})$ to represent a function but could not explain the meaning of function. The boy could also use algebraic expression $y=f(x)$ to interpret the variations of variables. I hereby concluded that example recognition is easier and earlier than meaning recognition. The former is concrete and may be perceived by sight. The latter is abstract and should be understood by insight and expressed by verbal statement. Both form the process of the formation of concept. Meaning understanding is the primary goal of concept learning.

\section{Research Method}

The researcher paid attention to the content related to function in the calculus curriculum and the presentations of the curriculum materials of function in the high school textbooks and then designed a curriculum unit on function including functional concepts (such as function, variables, definition domain, corresponding domain, range, function value, and extrema) and their properties (such as one to one, onto, increasing, decreasing, and invertible), types of functions (such as varieties of polynomial function, varieties of absolute value function, varieties of rational function, and varieties of irrational function), the operations of functions (such as addition, subtraction, multiplication, division, and composition), and the representations of function (such as verbal statement, algebraic expression, table, graph, arrow diagram, and machine analogue). The designed content had been sent to 4 experts to ask for advice and then the curriculum material was tried out in five classes called A, B, C, D, and E in this report in a private university of technology and science at Taipei. The students' academic abilities were below average in Taiwan. The students in Class E took classes during the night and worked during the day. Their academic performances were generally worse than students in other classes. The only teacher used 12 periods within 6 weeks to teach the students in each class the curriculum content. Lecture method was the major way for instruction. The related history of mathematics was provided and reported in the class to soften the curriculum materials.

To understand the students' learning achievements, a set of test items were designed. The test items contain two parts: the first part includes distinguishing whether a representation can represent a function and stating the reason and the second part includes the examinations of functional concepts and the properties of functions. The test items had been evaluated by 4 experts and they thought that the items were appropriate to test the students' understanding about function.

After the class of 12 periods, the test was administrated. There were 51, 49, 53, 54, and 45 students in the five classes who took the test. The test time was 70 minutes. After the test, the students' performances were graded and analyzed by using EXCEL to denote their performances: giving the score 2 for correct answer, the score 1 for half correctness, the notation " $\mathrm{x}$ " for incorrectness, " 0 " for inappropriate answer, and "?" for puzzled answer. Moreover, about 10 students in each class were interviewed to see their thinking and understanding.

\section{Data Analysis and Results}

The researcher had discussed with 4 other mathematics teachers about the outline and content of the curriculum unit. 
The 4 experts had no special opinion about the unit. They thought that the topic of function is basic and essential for studying function and calculus.

After testing, the standard of grading was given to the graders. Each examination paper was reviewed by another grader to assure precise grading.

There are 45 questions in the test and the total score is 90 . The rate of correctness of students in the 5 classes was $30.90 \%$. Their performances were poor. The rate of correctness of students in the best class was about one third. If we disregard the parts about stating reason or computation, the rate of correctness was $40.05 \%$ in the 5 classes. However, the rate of correctness in the parts about stating reason or computation was only $10.63 \%$.

The first three items asked students to distinguish whether the given representations in the three common forms: algebraic expression, table, and graph can represent functions and asked students to explain. The rate of correctness was $34.08 \%$. If we disregard the explanation parts, the rate of correctness was $57.28 \%$ but the rate of correctness of explanation was only $10.88 \%$. During interviews, more than half of the interviewee said that their answers for whether the representation is a function were due to guess and got the correct answers. Moreover, few students could state the definition of function. A few students could cite an example of a function and explain it. Their explanations used to be incomplete.

The fourth item including 5 sub-items was to examine students' functional concepts. The first sub-item was about function values. The given function is $f(x)=(3 x+1) /(x-1)$. The rate of correctness for $f(2)$ is $80.16 \%$. The rate of correctness for $\mathrm{f}(-1)$ is $69.05 \%$. However, the rate of correctness for finding the function value of $1 / 2$ is $21.83 \%$. To find the function value of 1 was the most difficult question for students to answer. The rate of correctness was only $18.65 \%$. Considering the results of interviews, I conclude that the students' computation accuracy depended on number systems. Moreover, many students were unclear about the meaning of "function value." Some of them mistook that it is to find pre-image. More than half of the students did not have exact idea about the denominator being 0 .

The second sub-item was about transforming an equation $x^{2} y=1$ into an algebraic expression of function and ask them to point out the independent variable and dependent variable and to give the reason. The rate of correctness for the 4 questions was $17.90 \%$. The rate of correctness is $27.45 \%$ if we ignore the part of give explanations. The rate of correctness for transforming the equation $x^{2} y=1$ into the function expression $y=1 / x^{2}$ was only $19.05 \%$. About $30 \%$ of the students could point out that the independent variable is $\mathrm{x}(30.95 \%)$ and dependent variable is y $(32.34 \%)$. However, only $7.14 \%$ of the students could give reasons.

The third and fourth sub-items asked students to find extrema of a rational function $\mathrm{f}(\mathrm{x})=1 / \mathrm{x}(3 \leqq x \leqq 7)$ and an irrational function $\mathrm{g}(\mathrm{x})=\sqrt{x+2} \quad(2 \leqq x \leqq 6)$. The rate of correctness was $47.67 \%$. Most students were unfamiliar with fractional numbers and radicals together with their properties and computations. It made the researcher think that adding the content of number systems into the pre-calculus course is indispensable.

The fifth sub-item provided questions about functional concepts including definition domain, corresponding domain, range, one to one, inverse function, and composite function and asked students to find range, inverse function, and composite function and to give explanations. The rate of correctness of all answers in the five classes was $11.61 \%$. The rate of correctness in the parts of finding range, inverse function, and composite function was only $1.09 \%$. The rate of correctness of other parts was $15.81 \%$. The students' performances were very poor in this sub-item. It made the researcher and the teachers consider the step of instruction.

\section{Conclusions, Discussions, and Suggestions}

The experts had no particular opinion about the designed content on function for the course. However, the content seemed to be difficult for students even though they had been taught the same content in high schools. For the learning of students of this level, the step of instruction should be slower. More interpretations in the classes are required.

From the test, we find that most students did not have clear recognition about function. Most students could not clearly distinguish whether a representation can represent a function. Some students used guessing to answer questions. Few students could give explanations for their answer. The accuracy of the students' computations was affected by different number systems and the degree of complication. Most students were not able to transform an equation to algebraic expression of a function. Only one third of the students could point out independent variable or dependent variable. In addition, many students were unclear about the meaning of "function value." Some of them mistook that it is to find pre-image. More than half of the students did not have exact idea about the denominator 
being 0 . To find extrema of a rational function or irrational function were difficult tasks for students. On the other hand, other functional concepts, including definition domain, corresponding domain, range, one to one, inverse function, and composite function, were difficult for students to understand. The procedures of finding range, inverse function, and composite function were more difficult to do.

Considering students' understandings and computations in numbers, the researcher thought that a unit on number systems is indispensable for pre-calculus course. The properties of numbers together with their computation procedures should be emphasized in the curriculum and instruction. In addition, the concepts of both set and function are unified concepts in mathematics. It is recommended that both units on number system and set be added to the pre-calculus course. The research group has hereby completed teaching materials on three topics, including number system, set, and function containing not only elementary content but also transcendental functions, such as Gaussian function, exponential functions, logarithmic functions, trigonometric functions, and inverse trigonometric functions.

On the other hand, the teacher found that students in this course were not diligent in learning, even when they went to class. The students cannot have good academic achievement if they lack diligence. How to motivate students' learning is the most important issue to teach the students of low level. On the other hand, the teacher did not find that students were more interested in listening the mathematical history. No questions related to history were given in the test to understand students' knowledge.

The major of the students in this study is mechanical engineering. Mathematics and calculus are important and essential for their learning. However, their performances in this study were not satisfactory. The instruction time for calculus in this department is only 2 periods per week. Each period lasts 50 minutes. I think that extra 2 periods should be added for the calculus course. Otherwise a pre-calculus course should be provided for freshmen in the first semester for about 30 periods. On the other hand, diligence and concentration are most important for learning. I think that class management should be more strict for students of the low level.

\section{References}

Fennema, E., Carpenter, T. P., \& Franke, M. (1992). Cognitively guided instruction. International Journal of Educational Research, 17(5), 457-470.

Liu, B. H. (2006). The observations and investigations on the related concepts with limit of students in the technological college. A paper as project achievement for the National Science Council in Taiwan.

Lovell, K. (1971). Some aspects of the growth of the concept of a function. In M. F. Rosskopf, L. P. Steffe, \& S. Taback (Eds.), Piagetian cognitive development research and mathematical education. Washington, D.C.: National council of Teachers of mathematics.

Lue, Y. T. (1985). Developing a descriptive statistics curriculum unit for the junior college of commerce. Unpublished doctoral dissertation, University of Georgia, Athens, Georgia.

Lue, Y. T. (2004). The formation and development of students' functional concepts. A paper as project achievement for the National Science Council in Taiwan.

Lue, Y. T. (2005a). The formation and learning difficulties of functional concepts of students in junior college. Northern Taiwan Journal, 28, 292-331.

Lue, Y. T. (2005b). The exploration of the formation and development of functional concepts. 2005 Int. Conf. on Learning, Teaching, and Evaluation (Abstract on p. 261 of Proceeding and paper on the disk L07). Taipei: National Taiwan Normal University Press.

Lue, Y. T. (2005c). The formation and learning difficulties of functional concepts of students in business college. Journal of National Taipei College of Business, 8, 131-166.

Lue, Y. T. (2005d). The learning difficulties and misconceptions on function of students in junior college of business. 2005 Cross Strait Conf. on Science and Technology. Yunlin: National Yunlin University of Science and Technology Press.

Lue, Y. T. (2007a). The horizontal transformations of different kinds of functions. A paper as project achievement for the National Science Council in Taiwan.

Lue, Y. T. (2007b). The students' horizontal transformations of different kinds of functions in junior college. The $23^{\text {rd }}$ Conf. of Science Education (Abstract on p. 128 of Proceeding, No. 174) .

Lue, Y. T. (2008a). Junior college students' doing horizontal transformations of algebraic functions. Northern Taiwan 
Journal, 31, 231-254.

Lue, Y. T. (2008b). The Horizontal Transformations of Algebraic Functions with Different Modalities. 2008 CASE (Conference of Asian Science Education: Science Education from an Asian Perspective). Abstract shown on p. 158 of the Proceeding. Full paper in a DVD (No. 89).

Markovits, Z., Eylon, B., \& Bruckheimer, M. (1986). Functions today and yesterday. For the Learning of Mathematics, 6(2), 18-28.

Markovits, Z., Eylon, B., \& Bruckheimer, M. (1988). Difficulties students have with the function concept. In A. F. Coxford \& A. P. Shulte (Eds.), The ideas of algebra, K-12 (pp. 43-60). Reston, VA: National Council of Teachers of Mathematics.

Tall, D., \& Vinner, S. (1981). Concept image and concept definition with particular reference to limits and continuity. Educational Studies in Mathematics, 12(2), 151-169. http://dx.doi.org/10.1007/BF00305619

Vinner, S., \& Dreyfus, T. (1989). Images and definitions for the concept of function. Journal for Research in Mathematics Education, 20, 356-366. http://dx.doi.org/10.2307/749441 